\title{
IGF-I, IGFBP-3 and breast cancer risk in women: The European Prospective Investigation into Cancer and Nutrition (EPIC)
}

S Rinaldi ${ }^{1}$, P H M Peeters ${ }^{2}$, F Berrino $^{3}$, L Dossus $^{1}, C$ Biessy $^{1}$, A Olsen $^{4}$, A Tjonneland ${ }^{4}, K$ Overvad $^{5}$, F Clavel-Chapelon ${ }^{6}, M C$ Boutron-Ruault ${ }^{6}$, B Téhard ${ }^{6}$, G Nagel $^{7}, J_{\text {Linseisen }}{ }^{7}$, H Boeing $^{8}$, P H Lahmann $^{8}$, A Trichopoulou $^{9}$,

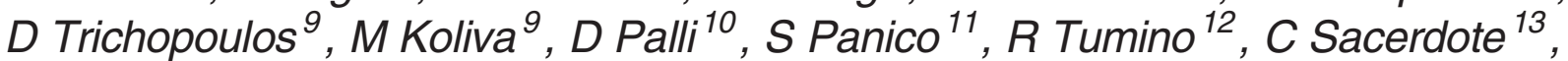
C H van Gils ${ }^{2}, P$ van Noord ${ }^{2}, D E$ Grobbee ${ }^{2}$, H B Bueno-de-Mesquita ${ }^{14}$, C A Gonzalez ${ }^{15}$, A Agudo $^{15}, M D$ Chirlaque ${ }^{16}$, A Barricarte $^{17}, N$ Larrañaga $^{18}$, J R Quiros ${ }^{19}$, S Bingham ${ }^{20}, K$ T Khaw $^{21}$, T Key $^{22}, N E$ Allen $^{22}$, A Lukanova $^{23}$, $N$ Slimani $^{1}$, R Saracci ${ }^{1}$, E Riboli $^{24}$ and $R$ Kaaks $^{1}$

\footnotetext{
${ }^{1}$ International Agency for Research on Cancer (IARC-WHO), 150 Cours Albert Thomas, 69372 Lyon, Cédex 08 , France

2 Julius Center for Health Sciences and Primary Care, University Medical Center, Utrecht, the Netherlands

${ }^{3}$ National Cancer Institute, Milan, Italy

${ }^{4}$ The Danish Cancer Society, Institute of Cancer Epidemiology, Copenhagen, Denmark

${ }^{5}$ Department of Clinical Epidemiology, Aalborg Hospital, Aarhus University Hospital, Aalborg, Denmark

${ }^{6}$ INSERM, Institut Gustave Roussy, Villejuif, France

${ }^{7}$ Division of Clinical Epidemiology, German Cancer Research Center, Heidelberg, Germany

${ }^{8}$ German Institute of Human Nutrition, Department of Epidemiology, Potsdam-Rehbrücke, Germany

${ }^{9}$ University of Athens Medical School, Athens, Greece

${ }^{10}$ Molecular and Nutritional Epidemiology Unit, CSPO, Scientific Institute of Tuscany, Florence, Italy

${ }^{11}$ Department of Clinical and Experimental Medicine, Federico II University, Naples, Italy

${ }^{12}$ Cancer Registry, Azienda Ospedaliera 'Civile M P Arezzo', Ragusa, Italy

${ }^{13}$ CPO-Piemonte, Torino, Italy

${ }^{14}$ Center for Nutrition and Health, National Institute for Public Health and the Environment, Bilthoven, the Netherlands

${ }^{15}$ Department of Epidemiology, Catalan Institute of Oncology, Barcelona, Spain

${ }^{16}$ Epidemiology Department, Murcia Health Council, Murcia, Spain

${ }^{17}$ Public Health Institute of Navarra, Pamplona, Spain

${ }^{18}$ Public Health Division of Gipuzkoa, Health Department of the Basque Country, Donostia-San Sebastian, Spain

${ }^{19}$ Public Health and Health Planning Directorate, Asturias, Spain

${ }^{20} \mathrm{MRC}$ Centre for Nutrition in Cancer Prevention and Survival, University of Cambridge, Department of Public Health and Primary Care, Cambridge, United Kingdom

${ }^{21}$ Clinical Gerontology Unit, Addenbrooke's Hospital, Cambridge, United Kingdom

${ }^{22}$ Epidemiology Unit, Cancer Research UK, University of Oxford, Oxford, United Kingdom

${ }^{23}$ New York University School of Medicine, New York, USA

${ }^{24}$ Imperial College, London, United Kingdom
}

(Requests for offprints should be addressed to R Kaaks; Email: kaaks@iarc.fr)

\begin{abstract}
Blood concentrations of insulin-like growth factor-I (IGF-I) and insulin-like growth factor binding protein-3 (IGFBP-3) have recently been associated with breast cancer risk, notably in women who developed breast cancer at a young age. Prospective studies published so far, however, were relatively small and odds ratio (OR) estimates imprecise. We present the results of a large prospective case-control study nested within the European Prospective Investigation into Cancer and Nutrition on total IGF-I, IGFBP-3 and breast cancer risk including 1081 incident cases of invasive breast cancer and 2098 matched control subjects. Increasing IGF-I and IGFBP-3 concentrations were associated with a significant increase in breast cancer risk in women who developed breast cancer after 50 years of age (highest vs lowest quintile OR 1.38 (95\% confidence interval (Cl) 1.02-1.86), $P=0.01$, and $1.44(95 \% \mathrm{Cl} 1.04-1.98), \quad P=0.01$,
\end{abstract}


respectively), but no relationship was observed in younger women ( $\mathrm{OR}=1.03(95 \% \mathrm{Cl} 0.60-1.77)$, $P=0.81$ for IGF-I, and $\mathrm{OR}=0.92(95 \% \mathrm{Cl} 0.50-1.70), P=0.69$ for IGFBP-3). There was, however, significant heterogeneity in the relationship of breast cancer with serum IGF-I and IGFBP-3 levels depending on the time interval between blood donation and tumor diagnosis. A reduction in breast cancer risk with increasing IGF-I concentrations was observed in cases with a diagnosis of cancer less than 2 years after blood donation, $(\mathrm{OR}=0.76(95 \% \mathrm{Cl} 0.57-1.03)$ ), while an increase in risk was observed for women with a later diagnosis (above or equal to two years after blood collection, $\mathrm{OR}=1.51$ (95\% Cl 1.19-1.91)). A similar pattern was observed for IGFBP-3. This study confirms previous findings for an association of serum IGF-I and IGFBP-3 concentrations with breast cancer risk, particularly for women with a later diagnosis of cancer, but it does not support the hypothesis of an involvement of IGF-I in younger women.

Endocrine-Related Cancer (2006) 13 593-605

\section{Introduction}

Insulin-like growth factor-I (IGF-I) is a polypeptide hormone that is involved in multiple cellular responses related to growth, including synthesis of DNA, RNA and cellular proteins (Jones \& Clemmons 1995). IGF-I stimulates cell proliferation and inhibits cell apoptosis in many cell types ( $\mathrm{Yu} \&$ Rohan 2000), including both normal and neoplastic breast epithelium (Sachdev \& Yee 2001). Its major binding protein insulin-like growth factor binding protein-3 (IGFBP-3) has been found not only to regulate IGF-I action, but also to have an IGF-I independent inhibitory effect on cell growth $(\mathrm{Yu} \&$ Rohan 2000).

Recently, four systematic reviews and meta-analyses (of both prospective and case-control studies) have been published on the relationship between total IGF-I and IGFBP-3 concentrations in blood and breast cancer (Renehan et al. 2004, Shi et al. 2004, Sugumar et al. 2004, Fletcher et al. 2005), which indicated an overall increase in breast cancer risk in premenopausal women with increasing endogenous levels of total IGF-I (between 42 and 74\% increase in risk for women in the highest IGF-I category vs women with IGF-I levels in the lowest category), while no association was observed for postmenopausal women. For circulating IGFBP-3, epidemiological studies have shown heterogeneous relationships with the risk of cancer, including that of breast tumors. A few studies showed a modest reduction in risk at the higher levels of IGFBP-3 (Bohlke et al. 1998, Chan et al. 1998, Hankinson et al. 1998, Ma et al. 1999, Giovannucci et al. 2000, Allen et al. 2005), whereas other studies showed an increase in risk (Del Giudice et al. 1998, Toniolo et al. 2000, Krajcik et al. 2002, Muti et al. 2002, Yu et al. 2002) or no association (Stattin et al. 2000, Kaaks et al. 2002, Palmqvist et al. 2002, Schernhammer et al. 2005). The aforementioned reviews and meta-analyses recently published on IGFBP-3 and breast cancer risk (Renehan et al. 2004, Shi et al. 2004, Sugumar et al. 2004, Fletcher et al. 2005) suggested an overall increase in breast cancer risk with increasing IGFBP-3 levels in blood in premenopausal women, but results were less consistent than for IGF-I. No association between IGFBP-3 and breast cancer was observed for postmenopausal women.

In this paper, we present results from a large case-control study nested within the European Prospective Investigation into Cancer and Nutrition (EPIC). In total, our study includes 1081 incident breast cancers and 2098 matched control subjects, and has approximately the same number of incident cases as all previously published cohort studies combined. Further advantages of the current study are the common methods used for the measurements of total IGF-I and IGFBP-3 that avoids the problem faced in meta-analyses of differences in absolute levels due to different methods of analyses, and the standardization of protocols for recruitment, blood collection and collection of questionnaire data on dietary and non-dietary variables.

\section{Material and methods}

\section{Study population}

The EPIC cohort consists of 366521 women and 153457 men, aged 35-69 years, recruited between 1992 and 1998 in 23 research centers in 10 Western European countries (Bingham \& Riboli 2004). Blood samples were collected from 365299 women and $151359 \mathrm{men}$, and extensive standardized questionnaire data on dietary and non-dietary variables, and anthropometric measurements were collected from all subjects. Questionnaires included detailed questions about habitual diet and physical activity, history of previous illness and surgical operations, and for women, menstrual and reproductive 
history, current and past use of oral contraceptives (OC) and postmenopausal hormone replacement therapy (HRT). Height, weight, and waist and hip circumferences were also measured, according to standardized protocols.

The present study includes breast cancer cases and control subjects from 19 recruitment centers in 8 of the participating countries: France, the Netherlands, the United Kingdom, Germany, Spain, Italy, Denmark and Greece.

\section{Collection and storage of blood samples}

In France, the Netherlands, the United Kingdom, Germany, Spain, Italy and Greece blood samples were collected according to a standardized protocol (Riboli et al. 2002). Serum, plasma, red cells and buffy coat were aliquoted in plastic straws of 0.5 $\mathrm{ml}$ each, which were heat-sealed and stored under liquid nitrogen $\left(-196^{\circ} \mathrm{C}\right)$. In Denmark, blood fractions were aliquoted into $1-\mathrm{ml}$ tubes, and stored in the vapor phase in liquid nitrogen containers $\left(-150^{\circ} \mathrm{C}\right)$.

\section{Follow-up for cancer incidence and vital status}

In Denmark, the Netherlands, the United Kingdom, and Spain and in most of the Italian centers, incident cancer cases were identified through record linkage with regional cancer registries. In Germany, France, Greece and Naples follow-up was based on a combination of methods, including health insurance records, cancer and pathology registries, and active follow-up through study subjects and their next-of-kin. Data on vital status in most EPIC study centers were collected from mortality registries at the regional or national level, in combination with data collected by active follow-up (Greece). For each EPIC study center, closure dates of the study period were defined as the latest dates of complete followup for both cancer incidence and vital status (dates varied between centers, between June 1998 and December 2000).

\section{Determination of menopausal status at blood donation}

Women were considered as premenopausal when they reported having had regular menses over the past twelve months, or when they were less than 42 years of age at recruitment. Women were considered as postmenopausal when they reported not having had any menses over the past 12 months, or when they reported bilateral ovariectomy, or when they were older than 55 . Women who were between 42 and 55 years of age, and who had missing or incomplete questionnaire data, or who reported previous hysterectomy (without ovariectomy), were classified as unknown.

\section{Selection of case and control subjects}

Case subjects were selected among women who developed breast cancer after their recruitment into the EPIC study, and before the end of the study period (defined for each study center by the latest end-date of follow-up). Women who used any hormone replacement therapy at the time of blood donation, or any exogenous hormones for contraception or medical purposes and who had a previous diagnosis of cancer (except non-melanoma skin cancer) were excluded from the study.

A total of 370 incident cases of invasive breast cancer were identified among women classified as premenopausal at the time of blood donation. A total of 614 incident cases of invasive cancer were identified as postmenopausal, and a total of 97 invasive breast cancer cases were identified among women who had unknown menopausal status at the time of blood donation.

For each case subject with breast cancer, two control subjects were chosen at random among appropriate risk sets consisting of all cohort members alive and free of cancer (except non-melanoma skin cancer) at the time of diagnosis of the index case. An incidence density sampling protocol for control selection was used, such that controls could include subjects who became a case later in time, while each control subject could also be sampled more than once. Matching characteristics for cases and controls were the study center where the subjects were enrolled in the cohort, menopausal status (premenopausal, postmenopausal, unknown), age ( \pm 6 months) at enrolment, time of the day at blood collection, fasting status $(<3 \mathrm{~h}, 3-6 \mathrm{~h},>6 \mathrm{~h})$ (Kaaks et al. 2005b), and, for premenopausal women, phase of menstrual cycle ('early follicular' (days $0-7$ of the cycle), 'late follicular' (days 8-11), 'peri-ovulatory' (days 12-16), 'midluteal' (days 2024) and 'other luteal' (days 17-19 or 25-40) (Kaaks et al. 2005a).

All participants had given their consent for future analyses of their blood samples and the Internal Review Board of the International Agency for Research on Cancer (IARC) had approved the hormone analyses. 


\section{Laboratory assays}

All hormone assays were performed at the IARC. Total IGF-I and IGFBP-3 were measured by enzyme-linked immunosorbent assays (ELISA) from Diagnostic Systems Laboratories (DSL, Webster, TX, USA). IGF-I assays included an acid-ethanol precipitation of IGF-I binding proteins, to avoid interference of IGFBPs with the IGF-I assay. Measurements were performed on never thawed serum sample aliquots. The laboratory personnel performing the assays were blinded as to the case/control status of the study subjects. Cases and matched controls were always analyzed in the same analytical batch. The mean intra-batch and inter-batch coefficients of variation were $6.2 \%$ and $16.2 \%$ respectively for IGF-I, and $7.2 \%$ and $9.7 \%$ respectively for IGFBP-3.

\section{Statistical analyses}

In all analyses, measurements of total IGF-I and IGFBP-3 were transformed using the natural logarithm to normalize their distributions. Correlations between IGF-I and IGFBP-3 adjusting for age, case/control status and batch were calculated as Pearson's partial correlation coefficients, on the full data set of cases plus controls, and by age group.

A pairwise $t$-test was used to test for mean case/ control differences in age at blood donation, age at diagnosis, age at first full term pregnancy, number of full term pregnancies, age at menarche, body mass index (BMI; calculated as kilograms divided by the square of the height expressed in meters), height, weight, and waist circumference, and hormone levels. A Chi-square test was used to test for case/control differences in parity and percentage of past hormone users. Odds ratios (ORs) for disease by quintile level of the hormone variables were estimated by conditional logistic regression models using the SAS 'PHREG' procedure (SAS Institute, Cary, NC, USA). The quintile cut-off points were based on the hormone variable distributions of the controls. Likelihood ratio tests were used to assess linear trends in ORs over the quintiles, scoring the quintile categories quantitatively as $1,2,3,4$ and 5 . All statistical tests and corresponding $P$-values were two-sided, and $P$-values $<0.05$ were considered statistically significant. For analysis of statistical heterogeneity, between study center/countries, or between subgroups of BMI, ORs were also estimated for continuous measurements of IGF-I and IGFBP-3 transformed on the $\log _{2}$ scale.
Formal tests of heterogeneity between the ORs in different EPIC subgroups were based on Chisquare statistics, calculated as the deviations of logistic beta-coefficients observed in each of the subgroups, relative to the overall beta-coefficient.

Multivariate conditional logistic regression was used to estimate ORs adjusted for possible confounders other than those controlled for by the matching criteria, including age at first full term pregnancy (nulliparous, $\leq 23,24-25,26-28, \geq 29+$ years, or missing), number of full term pregnancies $(0,1,2$, $3,4+$, or missing), age at menarche $(<12,12,13$, $14,15+$ years, or missing $)$, BMI $(<22.4,22.4-24.4$, 24.5-26.5, 26.6-29.6, $\geq 29.7$ ), and past use of HRT (never, previous, missing) or OC (never, previous, missing) and age at menopause $(\leq 43,44-47,48$ $50,51-52,53-54,>55$ years, missing). Adjustment of IGF-I for IGFBP-3 was made by a two-step procedure. First, in a linear regression model, values for IGF-I were regressed on IGFBP-3 levels and the residuals of these regressions were categorized into quintiles. Then, ORs were estimated for the quintiles of the residuals by multivariate conditional logistic regression models.

All statistical analyses were carried out using the SAS software package, version 8 (SAS Institute).

\section{Results}

Basic characteristics of case and matched control subjects at recruitment, according to the age at diagnosis of the cases ( $\leq 50$ or $>50$ years), are presented in Table 1. At a tumor diagnosis before or at age 50, breast cancer cases were older than control subjects when they had their first full-term pregnancy. Breast cancer cases who were older than 50 at the time of tumor diagnosis had fewer children compared with the controls, were slightly taller, had a higher body weight and a higher BMI.

Total IGF-I was inversely correlated with age both in postmenopausal women (Pearson $r=-0.13$, $P<0.0001)$ and in premenopausal women $(r=-0.28, P<0.0001)$. As reported in detail elsewhere (Gram et al. 2006), among the control subjects (both pre- and postmenopausal women) there was a non-linear relationship between BMI and serum levels of IGF-I, with highest IGF-I concentrations around a BMI of $26 \mathrm{~kg} / \mathrm{m}^{2}$, and there was a positive association $\left(P_{\text {trend }}=0.001\right)$ between BMI and IGFBP-3. In breast cancer cases, the same nonlinear relationship between BMI and total IGF-I was observed in postmenopausal women, but not in premenopausal women (results not shown). 


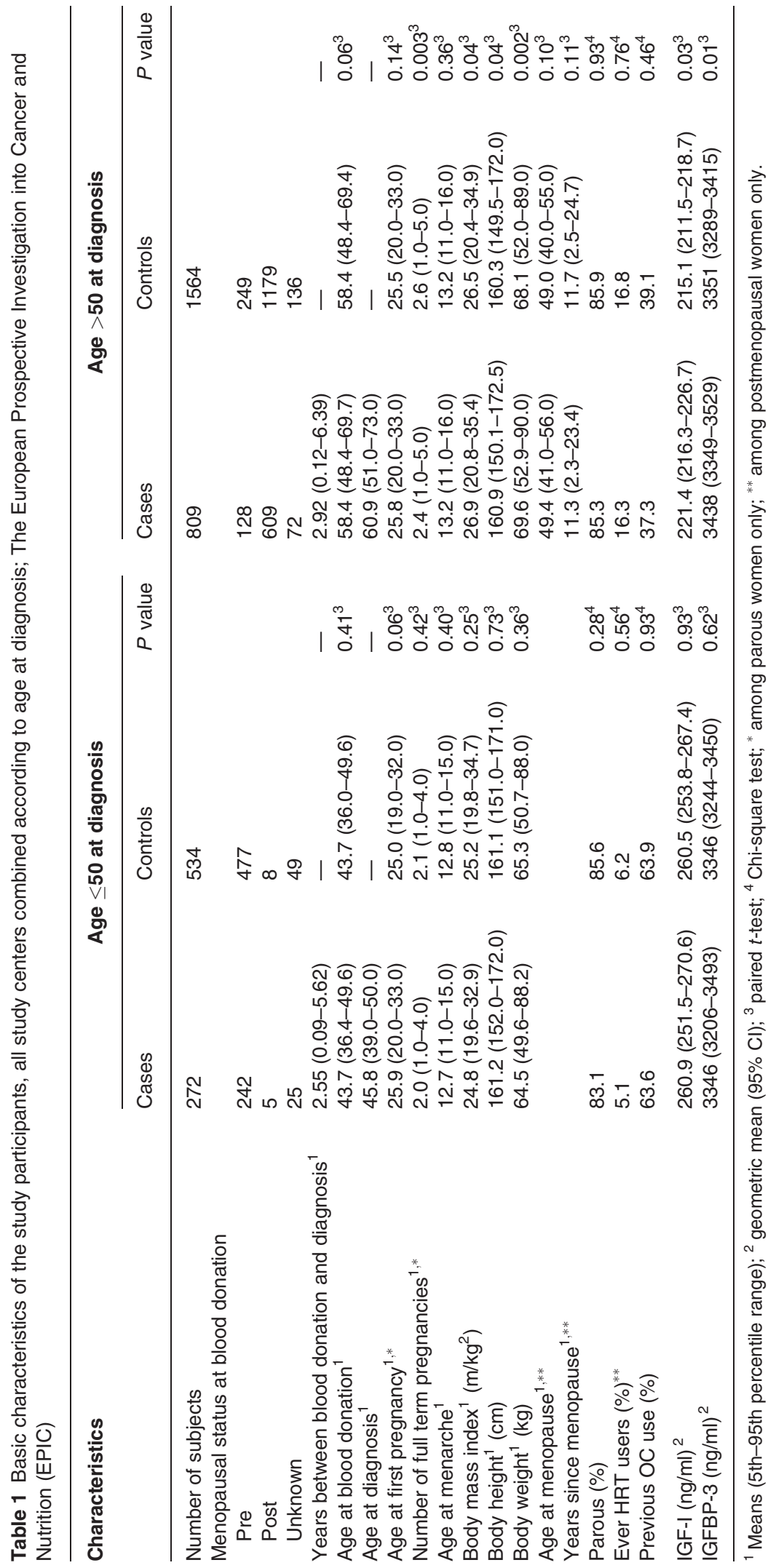


Table 2 Odds ratios of breast cancer (95\% confidence intervals) by quintiles of IGF-I and IGFBP-3 in all cancer cases, and their matched controls

\begin{tabular}{|c|c|c|c|c|c|c|}
\hline & \multicolumn{5}{|c|}{ Quintiles } & \multirow[b]{2}{*}{$\boldsymbol{P}_{\text {trend }}{ }^{*}$} \\
\hline & 1 & 2 & 3 & 4 & 5 & \\
\hline \multicolumn{7}{|l|}{ IGF-I } \\
\hline Crude $^{1}$ & 1.00 & $1.04(0.82-1.32)$ & $1.09(0.85-1.40)$ & $0.90(0.69-1.17)$ & $1.34(1.03-1.74)$ & 0.15 \\
\hline Adjusted $^{2}$ & 1.00 & $1.04(0.82-1.32)$ & $1.10(0.86-1.41)$ & $0.90(0.69-1.17)$ & $1.35(1.04-1.76)$ & 0.13 \\
\hline Adjusted $^{3}$ & 1.00 & $1.03(0.81-1.31)$ & $1.10(0.85-1.41)$ & $0.86(0.66-1.13)$ & $1.29(0.98-1.68)$ & 0.27 \\
\hline Number of cases/controls & $198 / 403$ & $207 / 403$ & $213 / 402$ & $174 / 403$ & $248 / 403$ & \\
\hline Residuals $^{2}$ & 1.00 & $1.08(0.84-1.39)$ & $0.91(0.70-1.19)$ & $1.03(0.79-1.35)$ & $1.21(0.91-1.61)$ & 0.34 \\
\hline Number of cases/controls & $204 / 389$ & $217 / 390$ & $180 / 391$ & $206 / 389$ & $229 / 390$ & \\
\hline \multicolumn{7}{|l|}{ IGFBP-3 } \\
\hline Crude $^{1}$ & 1.00 & $0.90(0.71-1.15)$ & $0.98(0.76-1.26)$ & $1.09(0.84-1.41)$ & $1.35(1.03-1.77)$ & 0.01 \\
\hline Adjusted $^{2}$ & 1.00 & $0.91(0.71-1.16)$ & $0.97(0.76-1.26)$ & $1.08(0.83-1.40)$ & $1.33(1.01-1.75)$ & 0.02 \\
\hline Adjusted $^{3}$ & 1.00 & $0.90(0.70-1.16)$ & $0.95(0.73-1.23)$ & $1.04(0.79-1.36)$ & $1.29(0.98-1.70)$ & 0.05 \\
\hline Number of cases/controls & $204 / 394$ & $188 / 407$ & $198 / 402$ & $209 / 388$ & $237 / 361$ & \\
\hline
\end{tabular}

* Linear trends in ORs over the quintiles by scoring the categories according to the quantitative score 1, 2, 3, 4 and 5 for quintile categories; 1 analysis matched on EPIC recruitment center, age at blood donation, menopausal status, phase of menstrual cycle, time of the day at blood donation, and fasting status; ${ }^{2}$ further adjustment for BMl; ${ }^{3}$ further adjustment for age at first full term pregnancy, number of full term pregnancies, age at menarche and previous use of oral contraceptives, previous use of HRT, age at menopause, time since menopause.

Total IGF-I concentrations were positively correlated with IGFBP-3 concentrations (Pearson $r=0.48, P<0.0001)$.

Over the whole study population, logistic regression analysis on the full set of breast cancer cases and controls (all age groups combined) suggested an overall increase of breast cancer risk with increasing total IGF-I and IGFBP-3 concentrations. The ORs for the highest vs lowest quintiles of IGF-I and IGFBP-3 were 1.29 (95\% CI 0.98-1.68) $\left(P_{\text {trend }}=0.27\right)$ and $1.29 \quad(95 \% \quad$ CI $\quad 0.98-1.70)$ $\left(P_{\text {trend }}=0.05\right)$ respectively, for a model adjusted for BMI, age at first full term pregnancy, number of full term pregnancies, previous use of oral contraceptives and age at menarche, previous use of HRT, age at menopause, and time since menopause (Table 2). Residuals of IGF-I, from a model regressing IGF-I on IGFBP-3, did not show any association with breast cancer risk.

When statistical analyses were restricted to breast cancer cases with tumor diagnosis before or equal to the age of 50, no association was found for total IGF-I or IGFBP-3 concentrations with breast cancer risk (OR between highest and lowest quintiles of $1.03(95 \%$ CI $0.60-1.77), P_{\text {trend }}=0.81$ for IGF-I; and $\mathrm{OR}=0.92(95 \%$ CI $0.50-1.70), P_{\text {trend }}=0.69$ for IGFBP-3) (Table 3). There was a similar lack of association when analyses were restricted to premenopausal women (OR highest vs lowest quintile of $1.18(95 \%$ CI $0.76-1.83), P_{\text {trend }}=0.61$; and OR 0.97 (95\% CI $0.58-1.62), P_{\text {trend }}=0.70$, for IGF-I and IGFBP-3 respectively), or further restricted to these women who were premenopausal and aged less than 50 at the time of blood donation (OR between highest and lowest quintile of $0.94(95 \%$ CI $0.54-1.64), P_{\text {trend }}=0.72$; and OR $1.01(95 \%$ CI $0.52-1.95), P_{\text {trend }}=0.88$, for IGF-I and IGFBP-3 respectively).

In women who had a diagnosis of breast cancer after 50 years of age, there was a direct, statistically significant relationship of breast cancer risk with increasing total IGF-I and IGFBP-3 concentrations (OR for highest vs lowest quintiles of 1.38 (95\% CI $1.02-1.86), P_{\text {trend }}=0.01$, for IGF-I; OR of 1.44 (95\% CI 1.04-1.98), $P=0.01$, for IGFBP-3) (Table 4). Similar results were obtained for women who were postmenopausal at blood donation (highest vs lowest quintile OR 1.29 (95\% CI $0.91-1.83)$, $P_{\text {trend }}=0.06$; and OR $1.45(95 \%$ CI $1.02-2.07)$, $P=0.06$, for IGF-I and IGFBP-3 respectively), or who were aged 55 or more at blood donation (highest vs lowest quintile OR 1.20 (95\% CI 0.84 $1.72), P_{\text {trend }}=0.13$; and $1.48(95 \%$ CI $1.03-2.11)$, $P_{\text {trend }}=0.03$, for IGF-I and IGFBP-3 respectively). This association of total IGF-I with breast cancer risk is also reflected by the fact that in this age group cases had significantly higher mean levels of IGF-I and IGFBP-3 compared with controls (Table 1).

Adjustments for BMI, age at full-term pregnancy, number of full-term pregnancies, age at menarche, previous use of oral contraceptives, previous use of HRT, age at menopause and time since menopause had only very minor effects on these estimated 
Table 3 Odds ratios of breast cancer (95\% confidence intervals) by quintiles of IGF-I and IGFBP-3 in cancer cases with age at diagnosis less or equal to 50 , and their matched controls

\begin{tabular}{|c|c|c|c|c|c|c|}
\hline & \multicolumn{5}{|c|}{ Quintiles } & \multirow[b]{2}{*}{$\boldsymbol{P}_{\text {trend }}{ }^{*}$} \\
\hline & 1 & 2 & 3 & 4 & 5 & \\
\hline \multicolumn{7}{|l|}{ IGF-I } \\
\hline Crude $^{1}$ & 1.00 & $1.10(0.69-1.74)$ & $0.94(0.58-1.52)$ & $0.90(0.55-1.46)$ & $1.02(0.61-1.70)$ & 0.76 \\
\hline Adjusted $^{2}$ & 1.00 & $1.11(0.70-1.76)$ & $0.97(0.60-1.57)$ & $0.92(0.56-1.50)$ & $1.04(0.62-1.74)$ & 0.83 \\
\hline Adjusted $^{3}$ & 1.00 & $1.07(0.66-1.74)$ & $0.95(0.57-1.57)$ & $0.88(0.53-1.47)$ & $1.03(0.60-1.77)$ & 0.81 \\
\hline Number of cases/controls & $55 / 106$ & $60 / 106$ & $50 / 104$ & $49 / 107$ & $56 / 105$ & \\
\hline Residuals $^{2}$ & 1.00 & $1.08(0.64-1.84)$ & $0.84(0.50-1.42)$ & $0.99(0.58-1.70)$ & $0.99(0.56-1.77)$ & 0.85 \\
\hline Number of cases/controls & $56 / 97$ & $53 / 96$ & $45 / 96$ & $50 / 96$ & $51 / 97$ & \\
\hline \multicolumn{7}{|l|}{ IGFBP-3 } \\
\hline Crude $^{1}$ & 1.00 & $0.89(0.55-1.45)$ & $0.99(0.59-1.67)$ & $0.80(0.46-1.39)$ & $0.97(0.55-1.71)$ & 0.82 \\
\hline Adjusted $^{2}$ & 1.00 & $0.88(0.54-1.43)$ & $0.98(0.58-1.66)$ & $0.77(0.44-1.36)$ & $0.98(0.55-1.75)$ & 0.83 \\
\hline Adjusted $^{3}$ & 1.00 & $0.87(0.52-1.46)$ & $1.00(0.58-1.74)$ & $0.74(0.41-1.34)$ & $0.92(0.50-1.70)$ & 0.69 \\
\hline Number of cases/controls & $53 / 96$ & $51 / 101$ & $54 / 95$ & $47 / 103$ & $52 / 92$ & \\
\hline
\end{tabular}

* Linear trends in ORs over the quintiles by scoring the categories according to the quantitative score 1, 2, 3, 4 and 5 for quintile categories; 1 analysis matched on EPIC recruitment center, age at blood donation, menopausal status, phase of menstrual cycle, time of the day at blood donation, and fasting status; ${ }^{2}$ further adjustment for $\mathrm{BMI} ;{ }^{3}$ further adjustment for age at first full term pregnancy, number of full term pregnancies, age at menarche and previous use of oral contraceptives.

relationships. Residuals of IGF-I, adjusted for IGFBP-3 through a linear regression model, did not show any significant association with breast cancer risk in any of the various subgroups.

Models showed a strong heterogeneity in estimated relationships of total IGF-I with breast cancer risk by duration of follow-up - i.e. the time between blood donation and tumor diagnosis (Fig. 1). Women who developed breast cancer less than two years after blood donation (410 cases) had a decrease in risk with increasing IGF-I concentrations (OR for a doubling of IGF-I concentrations of $0.76(95 \%$ CI $0.57-1.03))$, while those who developed breast cancer more than two years after blood donation (668 cases) had an increase in risk (OR of 1.51 (95\% CI 1.19-1.91); $\left.P_{\text {heterogeneity }}=0.0004\right)$. The two-years cut-off point was selected after performing an analysis of multislice 'cut-off' points, going backwards from 1, 2, 3 etc years. This heterogeneity of results was also

Table 4 Odds ratios of breast cancer (95\% confidence intervals) by quintiles of IGF-I and IGFBP-3 in cancer cases with age at diagnosis above 50 , and their matched controls

\begin{tabular}{|c|c|c|c|c|c|c|}
\hline & \multicolumn{5}{|c|}{ Quintiles } & \multirow[b]{2}{*}{$\boldsymbol{P}_{\text {trend }}{ }^{*}$} \\
\hline & 1 & 2 & 3 & 4 & 5 & \\
\hline \multicolumn{7}{|l|}{ IGF-I } \\
\hline Crude $^{1}$ & 1.00 & $0.96(0.72-1.28)$ & $1.04(0.79-1.38)$ & $1.14(0.86-1.52)$ & $1.47(1.10-1.97)$ & 0.005 \\
\hline Adjusted $^{2}$ & 1.00 & $0.95(0.71-1.26)$ & $1.04(0.78-1.38)$ & $1.15(0.86-1.54)$ & $1.46(1.09-1.96)$ & 0.005 \\
\hline Adjusted $^{3}$ & 1.00 & $0.90(0.67-1.21)$ & $1.03(0.77-1.37)$ & $1.11(0.83-1.49)$ & $1.38(1.02-1.86)$ & 0.01 \\
\hline Number of cases/controls & $149 / 312$ & $142 / 312$ & $151 / 310$ & $164 / 314$ & $202 / 312$ & \\
\hline Residuals $^{2}$ & 1.00 & $1.03(0.77-1.37)$ & $0.78(0.58-1.06)$ & $1.01(0.74-1.38)$ & $1.23(0.89-1.68)$ & 0.26 \\
\hline Number of cases/controls & $156 / 294$ & $161 / 292$ & $123 / 295$ & $157 / 292$ & $184 / 294$ & \\
\hline \multicolumn{7}{|l|}{ IGFBP-3 } \\
\hline Crude $^{1}$ & 1.00 & $0.90(0.68-1.19)$ & $0.96(0.72-1.29)$ & $1.16(0.87-1.56)$ & $1.54(1.13-2.09)$ & 0.002 \\
\hline Adjusted $^{2}$ & 1.00 & $0.90(0.68-1.19)$ & $0.95(0.71-1.28)$ & $1.14(0.85-1.53)$ & 1.49 (1.09-2.04) & 0.005 \\
\hline Adjusted $^{3}$ & 1.00 & $0.89(0.67-1.19)$ & $0.94(0.70-1.27)$ & $1.10(0.81-1.49)$ & $1.44(1.04-1.98)$ & 0.01 \\
\hline Number of cases/controls & $154 / 304$ & $139 / 310$ & $143 / 305$ & $161 / 289$ & $185 / 263$ & \\
\hline
\end{tabular}

* Linear trends in ORs over the quintiles by scoring the categories according to the quantitative score 1, 2, 3, 4 and 5 for quintile categories; 1 analysis matched on EPIC recruitment center, age at blood donation, menopausal status, time of the day at blood donation, and fasting status; ${ }^{2}$ further adjustment for BMl; ${ }^{3}$ further adjustment for age at first full term pregnancy, number of full term pregnancies, age at menarche and previous use of oral contraceptives, previous use of HRT, age at menopause, time since menopause. 


\begin{tabular}{|c|c|c|c|}
\hline \multicolumn{4}{|l|}{$\begin{array}{l}\text { Years between blood } \\
\text { donation and diagnosis }\end{array}$} \\
\hline $\begin{array}{l}\text { IGF1 } \\
\text { All women }\end{array}$ & $\begin{array}{c}\text { Cases/Controls } \\
1078 / 2088\end{array}$ & $\begin{array}{l}\text { OR } \\
1.15\end{array}$ & $\begin{array}{c}95 \% \mathrm{Cl} \\
0.96-1.38\end{array}$ \\
\hline$<2$ years & $410 / 791$ & 0.76 & $0.57-1.03$ \\
\hline$>=2$ years & $668 / 1297$ & 1.51 & $1.19-1.91$ \\
\hline $\begin{array}{l}\text { All women less than } 50 \text { at } \\
\text { diagnosis }\end{array}$ & $270 / 528$ & 1.06 & $0.71-1.56$ \\
\hline$<2$ years & $126 / 246$ & 0.58 & $0.33-1.02$ \\
\hline$>=2$ years & $144 / 282$ & 1.86 & $1.01-3.42$ \\
\hline $\begin{array}{l}\text { All women more than } 50 \text { at } \\
\text { diagnosis }^{2}\end{array}$ & $808 / 1560$ & 1.19 & $0.97-1.46$ \\
\hline$<2$ years & $284 / 545$ & 0.85 & $0.59-1.22$ \\
\hline$>=2$ years & $524 / 1015$ & 1.45 & $1.12-1.87$ \\
\hline \multicolumn{4}{|l|}{ IGFBP3 } \\
\hline All women ${ }^{2}$ & 1040/1952 & 1.27 & $0.98-1.63$ \\
\hline$<2$ years & $401 / 756$ & 0.93 & $0.60-1.45$ \\
\hline$>=2$ years & $639 / 1196$ & 1.49 & $1.08-2.06$ \\
\hline $\begin{array}{l}\text { All women less than } 50 \text { at } \\
\text { diagnosis }\end{array}$ & $257 / 483$ & 1.05 & $0.54-2.03$ \\
\hline$<2$ years & $123 / 233$ & 0.54 & $0.20-1.49$ \\
\hline$>=2$ years & $134 / 250$ & 1.61 & $0.60-4.29$ \\
\hline $\begin{array}{l}\text { All women more than } 50 \text { at } \\
\text { diagnosis }^{2}\end{array}$ & $783 / 1469$ & 1.33 & $1.01-1.76$ \\
\hline$<2$ years & $278 / 523$ & 1.10 & $0.65-1.86$ \\
\hline$>=2$ years & $505 / 946$ & 1.45 & $1.03-2.04$ \\
\hline
\end{tabular}

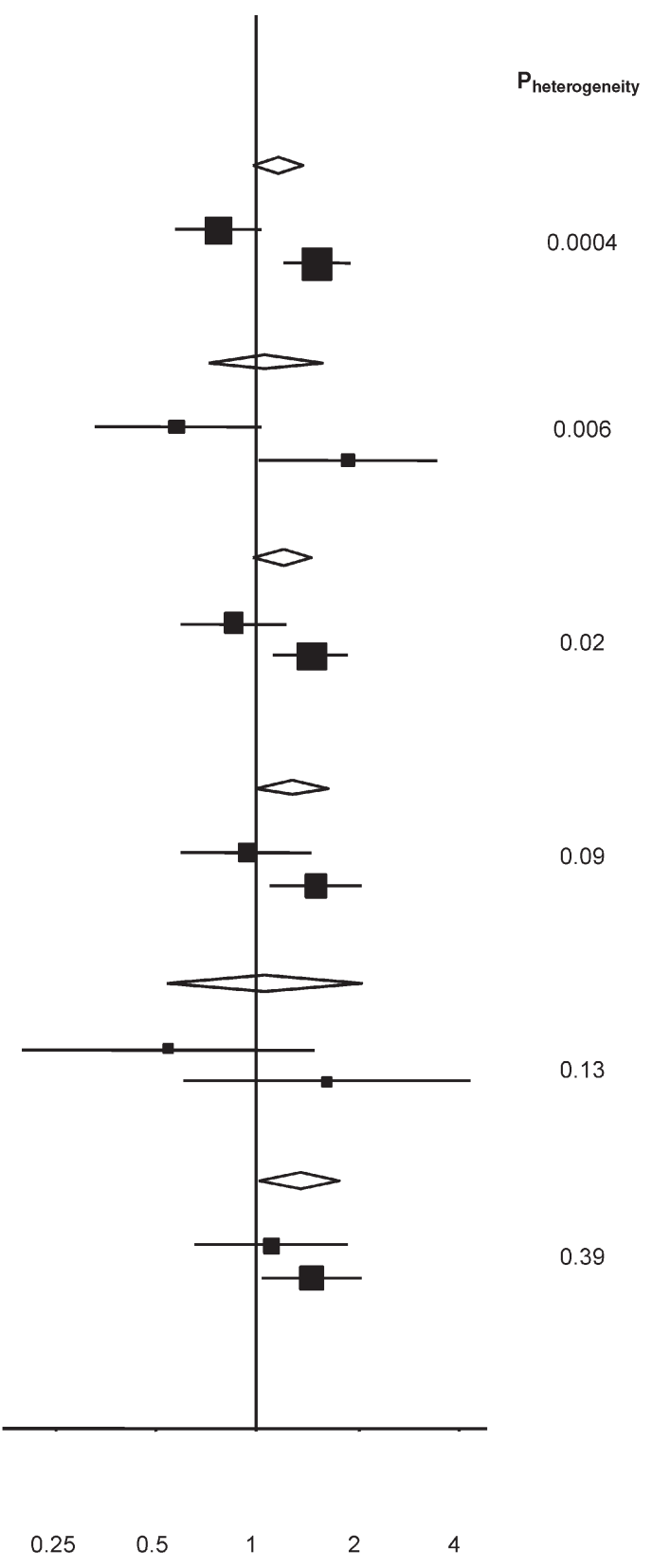

Figure 1 Odds ratios of breast cancer and 95\% confidence intervals for IGF-I and IGFBP-3 concentrations in cancer cases and their matched controls on a continuous $\log _{2}$ stratified by time since blood donation. ${ }^{1}$ Analysis matched on EPIC recruitment center, age at blood donation, menopausal status, time of day at blood donation and fasting status, and adjusted for BMI, age at first full-term pregnancy, number of full-term pregnancies, age at menarche and previous use of oral contraceptives. ${ }^{2}$ Further adjustment for previous use of HRT, age at menopause and time since menopause.

observed when looking at the residuals of IGF-I on IGFBP-3 $\left(P_{\text {heterogeneity }}=0.01\right)$ (results not shown). The same pattern was seen within subgroups of women with a tumor diagnosis up to the age of 50 , or beyond $(P$-values for heterogeneity of 0.006 and 0.02 respectively). Thus, among women who provided a blood sample at least two years before cancer diagnosis, increasing levels of IGF-I were associated with increasing breast cancer risk before the age of $50(\mathrm{OR}=1.86(95 \% \mathrm{CI} 1.01-3.42)$ for a doubling of IGF-I concentrations), as well as after the age of $50(\mathrm{OR}=1.45(95 \%$ CI $1.12-1.87))$. In contrast, for women with a follow-up of less than two years since blood donation an increase in total 


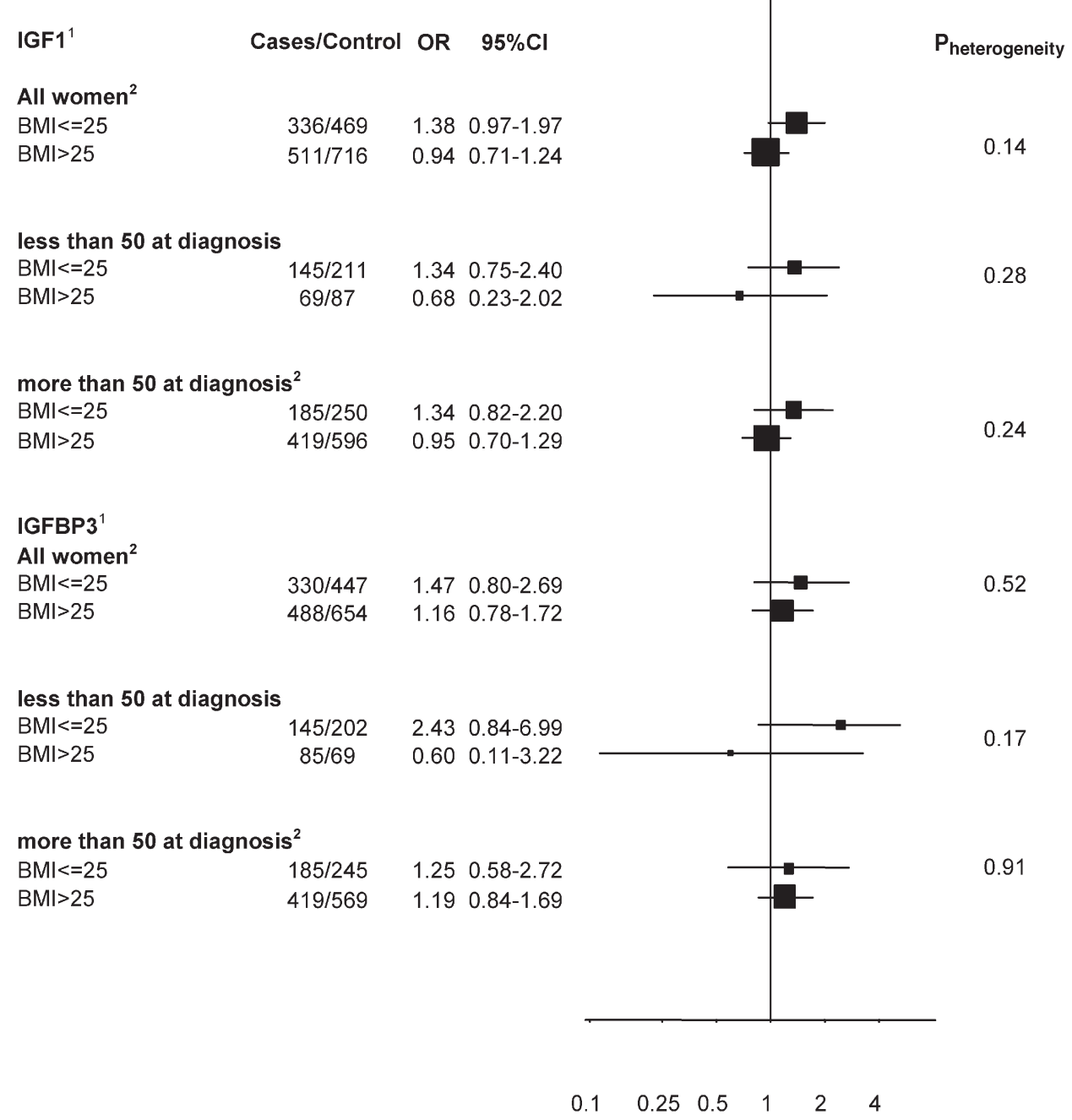

Figure 2 Odds ratios of breast cancer and 95\% confidence intervals on a continuous $\log _{2}$ scale of IGF-I and IGFBP-3 concentrations in cancer cases and their matched controls stratified by BMI. ${ }^{1}$ Analysis matched on EPIC recruitment center, age at blood donation, menopausal status, time of day at blood donation and fasting status, and adjusted for BMI, age at first full-term pregnancy, number of full-term pregnancies, age at menarche and previous use of oral contraceptives. ${ }^{2}$ Further adjustment for previous use of HRT, age at menopause and time since menopause.

IGF-I was associated with reduced cancer risks in both age groups $(\mathrm{OR}=0.58(95 \%$ CI $0.33-1.02)$ and 0.85 (95\% CI $0.59-1.22)$ respectively for a doubling of IGF-I concentrations), but the reduction in risk associated with IGF-I was not statistically significant in either of the age groups. For IGFBP-3, a similar association with breast cancer risk by duration of follow-up was observed on the whole population, and the same pattern could be seen when stratifying the analyses by age at diagnosis, although the heterogeneity did not reach statistical significance (Fig. 1).

Heterogeneity in OR estimates was also observed when stratifying the analyses by BMI (Fig. 2), and which was seen in both younger and older women (although the heterogeneity was not statistically significant). For all women with a BMI less than or equal to $25 \mathrm{~kg} / \mathrm{m}^{2}$, increasing IGF-I and IGFBP-3 levels were directly and positively related to breast cancer risk $(\mathrm{OR}=1.38(95 \%$ CI $0.97-1.97)$ and $\mathrm{OR}=1.47$ (95\% CI 0.80-2.69) respectively).

\section{Discussion}

In this prospective study - the largest, to date, on the relationship between breast cancer risk and total IGF-I and IGFBP-3 concentrations in blood - we observed an overall significant increase in breast 
cancer risk in women whose serum IGF-I and IGFBP-3 levels were within the upper part of the normal range. These relationships were more pronounced in women whose breast tumors were diagnosed after the age of 50, and no significant association was found in women who had a tumor diagnosis at a younger age. Residuals of IGF-I, adjusted for IGFBP-3 through a linear regression model, showed no relationship at all with breast cancer risk. There was significant heterogeneity of effect by duration of follow-up, however, with a statistically significant direct relationship of breast cancer risk (both before and after the age of 50) with IGF-I measured in blood samples collected at least two years before tumor diagnosis, and a small inverse relationship of risk with respect to IGF-I measured in blood samples collected more recently before diagnosis. The same heterogeneity by duration of follow-up was observed for the residuals of IGF-I.

The current study has the advantage of having a very large number of breast cancer cases for both young and relatively older women. Furthermore, its prospective design very much reduces the possibility that circulating hormone levels could have been influenced by the presence or diagnosis of the disease. In addition, standardized protocols were followed for recruitment and blood collection, questionnaire data, and hormone measurements, across sub-populations with heterogeneous lifestyles and cancer risks.

To some extent, our results contrast with those from previous prospective nested case/control studies. Increases in risk with increasing IGF-I concentrations have previously been observed in young women, either younger than 50 years of age at blood donation (Hankinson et al. 1998), or at cancer diagnosis (Toniolo et al. 2000, Krajcik et al. 2002, Muti et al. 2002, Renehan et al. 2004, Shi et al. 2004, Sugumar et al. 2004, Schernhammer et al. 2005). The inconsistency of our data with respect to previous study results might be partially explained by the different duration of follow-up: most previous prospective studies (Hankinson et al. 1998, Toniolo et al. 2000, Muti et al. 2002) had longer follow up periods (median follow-up time of 5.5 years for Muti et al., 10.5 years for Kraijcik et al., and 57 months for Toniolo et al. compared with 2.8 years of the present study). Most previous studies have observed no increase in risk for increasing levels of IGF-I in older women (Hankinson et al. 1998, Toniolo et al. 2000, Krajcik et al. 2002, Muti et al. 2002, Keinan-Boker et al. 2003, Gronbaek et al. 2004, Allen et al. 2005, Schernhammer et al. 2005), although an indication of an increase in risk with increasing IGF-I concentrations was observed in one previous prospective study (Kaaks et al. 2002), and in two case/control studies (Peyrat et al. 1993, Yu et al. 2002).

To our knowledge, our study is the first to show heterogeneity in the relationship of breast cancer with serum IGF-I levels depending on the time interval between blood donation and tumor diagnosis, and is also the first of a sufficiently large size to allow a precise examination of such heterogeneity. We do not have any clear biological explanation for this observation, however, and we could not identify any other effect modifier that could account for the observed heterogeneity. Careful analyses showed that the heterogeneity could not be attributed to differences in other reported characteristics between cancer cases who had earlier or later diagnoses, such as belonging to specific EPIC subcohorts, differences in BMI, reproductive or menstrual history, previous HRT use, endogenous sex hormone levels, or tumor characteristics. Screening could not explain the heterogeneity in the data, since the cases considered in the study had been diagnosed at least three months after blood collection, and the exclusion of the centers where women were recruited through breast cancer screening programs (Utrecht, the Netherlands, and Florence, Italy) did not change the associations.

A relative limitation of the study might be that blood samples have been collected only once over time. Therefore, we were not able to confirm the heterogeneity of results by measuring IGF-I and IGFBP-3 on samples taken one year apart from recruitment. However, it has been observed that the within-subject reproducibility within-subjects of serum IGF-I and IGFBP-3 concentrations over an average time of 14 months is relatively high (intraclass correlations of $0.66(95 \%$ CI $0.51-0.77)$ for IGF-I, and of $0.86 \quad(95 \%$ CI $0.89-0.91)$ for IGFBP-3 (Lukanova et al. 2004), indicating that a single blood measure is reasonably representative of the exposure over that period of time.

In the EPIC study, there is no information about menopausal status of the case subjects at cancer diagnosis. We therefore analyzed our data according to age at diagnosis, and age at blood donation. These two alternative classifications for subgroup analyses gave very similar results, so we decided to present our data analyzed by age at diagnosis. The similarity of results when using the two different classifications is not surprising, since more than 
$90 \%$ of women who had a diagnosis of cancer when they were less than 50 years of age, were premenopausal at blood donation, and they were on average 43.7 years old at blood donation. The lagtime between blood donation and diagnosis was on average 2.55 years (5th-95th percentile range: 0.09-5.62 years) for women aged less than 50 years at diagnosis. However, given this relatively short lag-time, plus the fact that the mean age at menopause was 49 years in this study population, it is likely that most women who developed a breast tumor before the age of 50 either were still premenopausal, or had gone into menopause only very recently. Conversely, about $15 \%$ of women recruited as premenopausal women had a diagnosis of breast cancer when they were older than 50 : considering a mean age at menopause of 49, some of these women could have become postmenopausal at the time of diagnosis. However, again, given the short follow-up time, they could only have gone into menopause very recently. It is very unlikely that the relationship between IGF-I levels and breast cancer risk would change abruptly through a change in menopausal status, because of the slow pace at which breast tumors develop, and because there is no evidence of a change in IGF-I levels according to menopausal status (apart from agerelated effects).

The only other risk factor that was found to modify, to some degree, the relationship of breast cancer risk with IGF-I was BMI. When looking at the overall population, IGF-I was found to be mildly positively associated with breast cancer risk only in lean women with a BMI lower than or equal to 25 (even though this association did not reach statistical significance), while no association was observed in overweight or obese women.

We monitored the quality of our total IGF-I measurements in blood, by comparison with previous ELISA total IGF-I assays (on a panel of about 30 serum samples), and by comparison with measurements obtained with different assays (immunoradiometric assays (IRMA) from DSL and from Immunotech, Marseille, France). Correlation coefficients between the repeated total IGF-I DSLELISA assays were systematically above 0.90 , and high correlation coefficients (above 0.80 ) were also observed when comparing measurements obtained by ELISA-DSL with those by the other commercial assays, and with in-house methods (Rinaldi et al. 2005). These results indicate that variations in the accuracy of different total IGF-I assays are unlikely to provide a key explanation for observed differences between the results from different epidemiological studies. Absolute levels were also comparable among methods and assay lots.

No association between IGFBP-3 concentrations in blood and breast cancer risk in young women was observed in the present study. This lack of association was present also when the analyses were restricted to women who were less than 50 years of age at diagnosis, those who were premenopausal and aged less than 50, and those who were less than 50 at recruitment in the study. Therefore, the results presented in our paper do not confirm the previous suggestion that total IGF-I and IGFBP-3 concentrations are mainly related to breast cancer in young women (Renehan et al. 2004, Shi et al. 2004, Sugumar et al. 2004). Some studies showed an increase in risk with increasing blood levels of IGFBP-3 (Toniolo et al. 2000, Kaaks et al. 2002, Muti et al. 2002), while others reported an inverse association of IGFBP-3 concentrations with breast cancer risk (Hankinson et al. 1998, Allen et al. 2005), and also with other cancers (Chan et al. 1998, Ma et al. 1999, Giovannucci et al. 2000, London et al. 2002). It has also been shown that different assays for IGFBP-3 measurements may lead to different conclusions on the relationship of this protein with cancer (Rinaldi et al. 2005), and it has been speculated that different assays may measure different, more or less intact forms of IGFBP-3 present in blood (Kaaks et al. 2001, Rinaldi et al. 2005).

In conclusion, the present study does not confirm previous observations of an increase in breast cancer risk with increasing IGF-I and IGFBP-3 concentrations in young women, but does show the association between these two proteins and breast cancer risk in older women.

\section{Acknowledgements}

We thank Prof. Carlo Campagnoli (Unit of Endocrinological Gynecology, Sant'Anna Gynecological Hospital, Turin, Italy) for his valuable comments on the manuscript, Mr Achaintre, Mrs Bouzac and Mrs Robinot for their valuable and meticulous work in performing all the laboratory analyses and Mrs Dehedin for her important secretarial help.

Specific study results of this nested case/control study within EPIC were obtained with financial support from the US Army Medical Research and Material Command (DAMD17-01-0275).

The EPIC study was funded by the 'Europe Against Cancer' Programme of the European Commission (SANCO); Ligue contre le Cancer (France); 
Société 3M (France); Mutuelle Générale de l'Education Nationale; Institut National de la Santé et de la Recherche Médicale (INSERM); German Cancer Aid; German Cancer Research Center; German Federal Ministry of Education and Research; Danish Cancer Society; Health Research Fund (FIS); ISCIII Network, RCESP (c03/09) Spain; of the Spanish Ministry of Health; the participating regional governments and institutions of Spain; Cancer Research UK; Medical Research Council, UK; the Stroke Association, UK; British Heart Foundation; Department of Health, UK; Food Standards Agency, UK; the Wellcome Trust, UK; Greek Ministry of Health; Greek Ministry of Education; Italian Association for Research on Cancer; Italian National Research Council; Compagnia di San Paolo; Dutch Ministry of Public Health, Welfare and Sports; Dutch Ministry of Health; Dutch Prevention Funds; LK Research Funds; Dutch ZON (Zorg Onderzoek Nederland); World Cancer Research Fund (WCRF); Swedish Cancer Society; Swedish Scientific Council; Regional Government of Skane, Sweden; Norwegian Cancer Society. The authors declare that there is no conflict of interest that would prejudice the impartiality of this scientific work.

\section{References}

Allen NE, Roddam AW, Allen DS, Fentiman IS, Dos SS, I, Peto J, Holly JM \& Key TJ 2005 A prospective study of serum insulin-like growth factor-I (IGF-I), IGF-II, IGF-binding protein-3 and breast cancer risk. British Journal of Cancer 92 1283-1287.

Bingham S \& Riboli E 2004 Diet and cancer - the European Prospective Investigation into Cancer and Nutrition. Nature Reviews in Cancer 4 206-215.

Bohlke K, Cramer DW, Trichopoulos D \& Mantzoros CS 1998 Insulin-like growth factor-I in relation to premenopausal ductal carcinoma in situ of the breast. Epidemiology 9 570-573.

Chan JM, Stampfer MJ, Giovannucci E, Gann PH, Ma J, Wilkinson P, Hennekens CH \& Pollak M 1998 Plasma insulin-like growth factor-I and prostate cancer risk: a prospective study. Science 279 563-566.

Del Giudice ME, Fantus IG, Ezzat S, McKeown-Eyssen G, Page D \& Goodwin PJ 1998 Insulin and related factors in premenopausal breast cancer risk. Breast Cancer Research and Treatment 47 111-120.

Fletcher O, Gibson L, Johnson N, Altmann DR, Holly JM, Ashworth A, Peto J \& Silva IS 2005 Polymorphisms and circulating levels in the insulin-like growth factor system and risk of breast cancer: a systematic review. Cancer Epidemiology Biomarkers and Prevention 14 2-19.
Giovannucci E, Pollak M, Platz EA, Willett WC, Stampfer MJ, Majeed N, Colditz GA, Speizer FE \& Hankinson SE 2000 Insulin-like growth factor I (IGF-I), IGF-binding protein-3 and the risk of colorectal adenoma and cancer in the Nurses' Health Study. Growth Hormone and IGF Research 10 Suppl A S30-S31.

Gram I, Norat T, Rinaldi S, Dossus L, Lukanova A, Tehard B, Clavel-Chapelon F, Van Gils CH, Van Noord PA, Peeters PHM et al. Body mass index, waist-hip ratio and serum levels of IGF-I and IGFBP-3 in European women. International Journal of Obesity In Press.

Gronbaek H, Flyvbjerg A, Mellemkjaer L, Tjonneland A, Christensen J, Toft SH \& Overvad K 2004 Serum insulin-like growth factors, insulin-like growth factor binding proteins, and breast cancer risk in postmenopausal women. Cancer Epidemiology Biomarkers and Prevention 13 1759-1764.

Hankinson SE, Willett WC, Colditz GA, Hunter DJ, Michaud DS, Deroo B, Rosner B, Speizer FE \& Pollak M 1998 Circulating concentrations of insulin-like growth factor-I and risk of breast cancer. Lancet 351 1393-1396.

Jones JI \& Clemmons DR 1995 Insulin-like growth factors and their binding proteins: biological actions. Endocrine Reviews 16 3-34.

Kaaks R, Rinaldi S, Lukanova A, Akhmedkhanov A, Zeleniuch-Jacquotte A \& Toniolo P 2001 Correspondence re: Giovannucci et al. 2000 A prospective study of plasma insulin-like growth factor-I and binding protein-3 and risk of colorectal neoplasia in women. Cancer Epidemiology Biomarkers and Prevention 9 345-349. Cancer Epidemiology Biomarkers and Prevention 10 1103-1104.

Kaaks R, Lundin E, Rinaldi S, Manjer J, Biessy C, Soderberg S, Lenner P, Janzon L, Riboli E, Berglund G \& Hallmans G 2002 Prospective study of IGF-I, IGF-binding proteins, and breast cancer risk, in northern and southern Sweden. Cancer Causes Control 13 307-316.

Kaaks R, Berrino F, Key T, Rinaldi S, Dossus L, Biessy C, Secreto G, Amiano P, Bingham S, Boeing H et al. 2005 a Serum sex steroids in premenopausal women and breast cancer risk within the European Prospective Investigation into Cancer and Nutrition (EPIC). Journal of the National Cancer Institute 97 755-765.

Kaaks R, Rinaldi S, Key TJ, Berrino F, Peeters PH, Biessy C, Dossus L, Lukanova A, Bingham S, Khaw KT, Allen N et al. $2005 b$ Postmenopausal serum androgens, oestrogens and breast cancer risk; the European Prospective Investigation into Cancer and Nutrition (EPIC). Endocrine-Related Cancer 12 1071-1082.

Keinan-Boker L, Bueno-de-Mesquita HB, Kaaks R, Van Gils CH, Van Noord PA, Rinaldi S, Riboli E, Seidell JC, Grobbee DE \& Peeters PH 2003 Circulating levels of insulin-like growth factor I, its binding proteins $-1,-2,-3$, C-peptide and risk of postmenopausal breast cancer. International Journal of Cancer 106 90-95.

Krajcik RA, Borofsky ND, Massardo S \& Orentreich N 2002 Insulin-like growth factor I (IGF-I), IGF-binding proteins, and breast cancer. Cancer Epidemiology Biomarkers and Prevention 11 1566-1573. 
London SJ, Yuan JM, Travlos GS, Gao YT, Wilson RE, Ross RK \& Yu MC 2002 Insulin-like growth factor I, IGF-binding protein 3 , and lung cancer risk in a prospective study of men in China. Journal of the National Cancer Institute 94 749-754.

Lukanova A, Zeleniuch-Jacquotte A, Lundin E, Micheli A, Arslan AA, Rinaldi S, Muti P, Lenner P, Koenig KL, Biessy C, Krogh V, Riboli E, Shore RE, Stattin P, Berrino F, Hallmans G, Toniolo P \& Kaaks R 2004 Prediagnostic levels of C-peptide, IGF-I, IGFBP-1, -2 and -3 and risk of endometrial cancer. International Journal of Cancer 108 262-268.

Ma J, Pollak MN, Giovannucci E, Chan JM, Tao Y, Hennekens CH \& Stampfer MJ 1999 Prospective study of colorectal cancer risk in men and plasma levels of insulin-like growth factor (IGF)-I and IGF-binding protein-3. Journal of the National Cancer Institute $\mathbf{9 1}$ 620-625.

Muti P, Quattrin T, Grant BJ, Krogh V, Micheli A, Schunemann HJ, Ram M, Freudenheim JL, Sieri S, Trevisan M \& Berrino F 2002 Fasting glucose is a risk factor for breast cancer: a prospective study. Cancer Epidemiology Biomarkers and Prevention 11 1361-1368.

Palmqvist R, Hallmans G, Rinaldi S, Biessy C, Stenling R, Riboli E \& Kaaks R 2002 Plasma insulin-like growth factor-I, insulin-like growth factor binding protein-3, and risk of colorectal cancer: a prospective study in northern Sweden. Gut 50 642-646.

Peyrat JP, Bonneterre J, Hecquet B, Vennin P, Louchez MM, Fournier C, Lefebvre J \& Demaille A 1993 Plasma insulin-like growth factor-I (IGF-I) concentrations in human breast cancer. European Journal of Cancer 29A 492-497.

Renehan AG, Zwahlen M, Minder C, O'Dwyer ST, Shalet SM \& Egger M 2004 Insulin-like growth factor (IGF)-I, IGF binding protein-3, and cancer risk: systematic review and meta-regression analysis. Lancet 363 1346-1353.

Riboli E, Hunt KJ, Slimani N, Ferrari P, Norat T, Fahey M, Charrondiere UR, Hemon B, Casagrande C, Vignat J et al. 2002 European Prospective Investigation into Cancer and
Nutrition (EPIC): study populations and data collection. Public Health Nutrition 5 1113-1124.

Rinaldi S, Kaaks R, Zeleniuch-Jacquotte A, Arslan AA, Shore RE, Koenig KL, Dossus L, Riboli E, Stattin P, Lukanova A \& Toniolo P 2005 Insulin-like growth factor-I, IGF binding protein-3, and breast cancer in young women: a comparison of risk estimates using different peptide assays. Cancer Epidemiology Biomarkers and Prevention 14 48-52.

Sachdev D \& Yee D 2001 The IGF system and breast cancer. Endocrine-Related Cancer 8 197-209.

Schernhammer ES, Holly JM, Pollak MN \& Hankinson SE 2005 Circulating levels of insulin-like growth factors, their binding proteins, and breast cancer risk. Cancer Epidemiology Biomarkers and Prevention 14 699-704.

Shi R, Yu H, McLarty J \& Glass J 2004 IGF-I and breast cancer: a meta-analysis. International Journal of Cancer $111418-423$.

Stattin P, Bylund A, Rinaldi S, Biessy C, Dechaud H, Stenman UH, Egevad L, Riboli E, Hallmans G \& Kaaks R 2000 Plasma insulin-like growth factor-I, insulin-like growth factor-binding proteins, and prostate cancer risk: a prospective study. Journal of the National Cancer Institute 92 1910-1917.

Sugumar A, Liu YC, Xia Q, Koh YS \& Matsuo K 2004 Insulin-like growth factor (IGF)-I and IGF-binding protein 3 and the risk of premenopausal breast cancer: a meta-analysis of literature. International Journal of Cancer 111 293-297.

Toniolo P, Bruning PF, Akhmedkhanov A, Bonfrer JM, Koenig KL, Lukanova A, Shore RE \& Zeleniuch-Jacquotte A 2000 Serum insulin-like growth factor-I and breast cancer. International Journal of Cancer 88 828-832.

Yu H \& Rohan T 2000 Role of the insulin-like growth factor family in cancer development and progression. Journal of the National Cancer Institute 92 1472-1489.

Yu H, Jin F, Shu XO, Li BD, Dai Q, Cheng JR, Berkel HJ \& Zheng W 2002 Insulin-like growth factors and breast cancer risk in Chinese women. Cancer Epidemiology Biomarkers and Prevention 11 705-712. 
